\title{
The effects of scientific literacy on participation to political decision making
}

\author{
Ahmet Süerdem ${ }^{1 \mathrm{a}}$, and Sandy Çağlıyor ${ }^{1}$ \\ ${ }^{1}$ Bilgi University, Kazım Karabekir Cad. No: 2/13, Istanbul and Postcode, 34060
}

\begin{abstract}
The low levels of scientific literacy among the general public in a society where technology penetrates all aspects of everyday life creates major citizenship problems. One of the main goals of education is increasing the civic scientific literacy of the citizens besides preparing students for science based vocations. Well educated human capital stock is important for informed decision making as well as the development of research and development activities. The quality of policy decisions is highly dependent on the level of interest, information and attitudes towards S\&T. Making conscious decisions about S\&T related developments is substantial for democratic participation of the public to policy making. Increasing complexity of science and technology related issues creates a gap between expert and citizen knowledge. Scientific literacy decreases this gap in terms of creating a knowledgeable approach to the controversies around scientific issues. The aim of this study is to make an operational model for explaining how civic scientific literacy affects public understanding of science and these in turn influence participation to political decision making. We analyse the effects of scientific literacy and other public understanding of science variables on participation to political decision making.
\end{abstract}

Keywords:Political decision making; science education; scientific literacy; public understanding of science; path analysis

\section{Introduction}

The low levels of scientific literacy among the general public in a society where technology penetrates all aspects of everyday life creates major citizenship problems. One of the main goals of education is increasing the civic scientific literacy of the citizens besides preparing students for science based vocations. Well educated human capital stock is important for informed decision making as well as the development of research and development activities. The quality of policy decisions is highly dependent on the level of interest, information and attitudes towards S\&T. Making conscious decisions about S\&T related developments is substantial for democratic participation of the public to policy making.

\footnotetext{
${ }^{a}$ Corresponding author: ahmet.suerdem@bilgi.edu.tr
} 
Increasing complexity of science and technology related issues creates a gap between expert and citizen knowledge. Scientific literacy decreases this gap in terms of creating a knowledgeable approach to the controversies around scientific issues.

According to American National Academy of Sciences [5], "scientific literacy is the knowledge and understanding of scientific concepts and processes required for personal decision making, participation in civic and cultural affairs, and economic productivity". Lack of scientific literacy creates docility on the side of the public and discourages civic participation in decision making. According to Miller, [5] a science literate public is essential for the democratic process to function in today's highly technological societies. Without at least a general understanding of the issues they are called on to decide, voters will not be able to make healthy choices. Hence, studying the relationships between civic scientific literacy and public understanding of science is important to understand public participation to political decisions.

The aim of this study is to make an operational model for explaining how civic scientific literacy affects public understanding of science and these in turn influence participation to political decision making.

\subsection{Theory and model specification}

Our model takes into account that the relationship between civic scientific literacy and political decision making is not a straight forward one. One of the major aims of education is to increase scientific literacy, promote interest, engagement, involvement to science. Hence, the simplest model would assume direct effects of scientific literacy, education, interest, involvement and engagement on participation to political decision making as dependent variable. However, this basic model requires substantial revisions since the relationships between these variables are more complex. First, scientific literacy itself is the product of cultural capital. Cultural capital can be defined as the informedness, skills, education, and opportunities that endow a person with the attitudes and knowledge needed to achieve competency in social life, [1]. People develop long-term socialized value predispositions which they cultivate through educational systems and cultural values. They acquire basic beliefs and cognition about science through formal and informal education. While basic science literacy is internalized through formal education, informal activities such as engaging in mass media and science museums usually update this knowledge, [2]. George and Kaplan, [3] reported that children of the families who provided them with environments interacting with the schoolwork such as taking them to libraries and science museums or maintaining information resources such as books or magazines were more successful in terms of achieving scientific literacy. Hence, we cannot take education only as a control variable as the simple model suggests, but need to consider it as a spurious variable interacting with a variety of contextual variables making up the relations between cultural capital and scientific literacy.

Scientific literacy entails being able to read and understanding articles about science in the popular press and to engage in social conversation about the validity of the conclusions. Scientific literacy implies that a person can identify scientific issues underlying national and local decisions and express positions that are scientifically and technologically informed. A literate citizen should be able to evaluate the quality of scientific information on the basis of its source and the methods used to generate it.

After setting the context for the interaction of cultural capital relevant variables on scientific literacy, we need consider the fact that its relation to participation to decision making is mediated and moderated by a number of variables. We can define public participation as the practices involving the public in the agenda-setting, decision-making, and policy-forming activities of organizations/ institutions responsible for policy 
development, [6]. S\&T issues are a part of wider political debate either communicated or not by the science decision making authorities. These authorities should negotiate and clarify areas of incomplete knowledge even in the case that sharing power and responsibility could impinge scientific development. Decoupling public involvement to science from the discourse of scientists carries the danger of isolation of scientists from the interests, concerns and knowledge of public, [4]. If the public is not empowered to deal successfully with the science and technologies in their everyday lives, then it is highly likely that they would receive new technologies as alien forces as the unknown provokes fear and reactions. Hence, capability of citizens in involving collective decision making procedures is an important factor on participation to political decision making. This capability is provided by being actively involved in everyday layperson research activities such as reading articles on popular science in newspapers, magazines, searching the Internet for science topics. Combined with involving into debates with friends, these activities ground the passively acquired scholar knowledge; i.e. scientific literacy; into practical everyday political context. These involvement factors form a conative element which connects knowledge to behaviour. Cognition refers to the process of understanding and knowing the "what" of an issue, while conation refers to the "why". It is deliberate, intentional and proactive as opposed to the predispositional and habitual aspect of behaviour. Hence, conation turns passively internalized cognitive procedures into an act of volition to make goal-oriented decisional choices.

To complete our model, we include interestedness as a proxy for affect which is another mental activity which mediates between cognition and conation. Affect refers to one's attachment (positive or negative) to people, objects, ideas, etc. and how one feels about the information or knowledge about these. In our model we operationalize the affective component as the degree of interestedness about S\&T related issues compared to the others. It mediates between cognitive scientific literacy and conative involvement variables.

\section{Method}

\subsection{Respondents}

We used The SPECIAL EUROBAROMETER N³40-2005 ("Science and Technology") and covers the population of EU Member States, two candidate countries (Croatia and Turkey) and Switzerland, Iceland and Norway. Primary data for statistical analyses and related documentation (basic bilingual questionnaires, national field questionnaire versions and variable reports) are available online by GESIS, [7].

\subsection{Instruments}

\subsubsection{Civic scientific literacy}

According to Hazen (2002) scientific literacy is a mix of concepts and mentality for understanding the scientific issues of our times. Today, measuring civic scientific literacy basically is built upon a set of open-ended items, several multi-part questions, and a closedended true-false quiz that was established as the result of the 1988 U.K.-U.S. collaboration. Because of the difficulty of asking too many open-ended and difficult questions, large scale surveys such as Eurobarometers, concentrate on the third part of this set. Hence, we used quiz questions in the Eurobarometer survey to measure civic scientific literacy. Place the figure as close as possible after the point where it is first referenced in 
the text. If there is a large number of figures and tables it might be necessary to place some before their text citation.

\subsubsection{Interest and information level}

To measure interest and information level for science and technology we formed an composite index of the items asking how interested and informed the respondent about the following issues is: New medical discoveries; Environmental problems; New scientific discoveries and technological developments and are measured on a 4 point scale. We calculated the index scores through categorical factor analysis.

\subsubsection{Active involvement to S\&T related information seeking}

We made a composite index bringing together actively reading articles on science in newspapers, magazines, or on the Internet and talking with friends about science and technology items.

\subsubsection{Political participation}

We have measured participation to political decision making with the following item: "think I have something to offer in decisions about politics and current affairs".

\subsubsection{Analysis}

Path analysis by AMOS (Arbuckle \& Wothke, 1999) was used to determine the pathways by which the S\&T relevant cognitive, affective and conative variables interact to influence participation to political decision making. Figure 1 presents a set of hypotheses about the relations between variables based on the model we have specified. All of the fit indices fulfil the cut-off criteria recommended by Hu and Bentler (1999): TLI $=0.949 ; \mathrm{CFI}=0.993$ $\mathrm{RMSEA}=0.059$, along with the $\mathrm{CMIN} / \mathrm{DF}=111.485$.

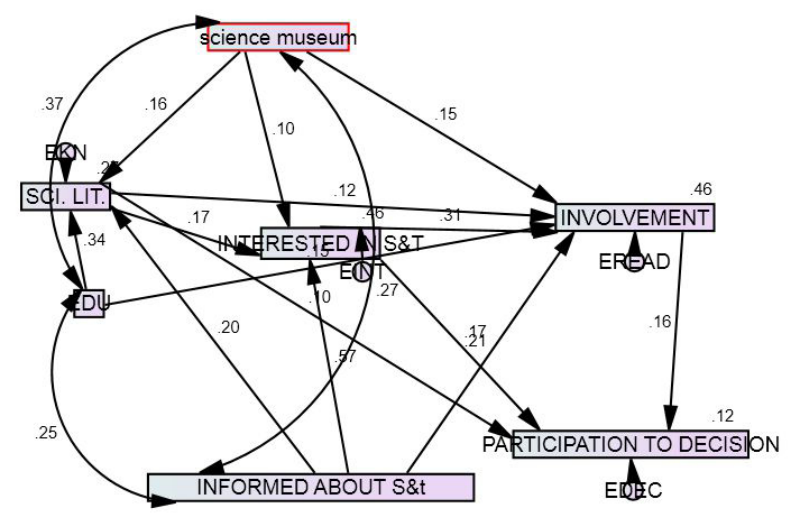

Fig. 1. Hypothesized pathways between the cognitive, affective and conative variables relevant to public understanding of science and participation to political decision making (Numbers denote direct effects, all $\mathrm{p}<.001)$. 


\section{Results}

Table 1. presents the standardized total effect sizes of independent variables on dependent variables. Scientific literacy has a weak-moderate total effect $(0.153)$ on participation to political decision making. Highest effect comes from interest to science news (0.215), followed by being informed about science through media (0.186) and active involvement in science related subjects through information search or discussing with friends (0.160). Education (0.075) and visiting science museums (0.072) have weak effects.

Table 1. Total Effects

\begin{tabular}{|l|rrrrrr|}
\hline & Information & Education & $\begin{array}{c}\text { Science } \\
\text { Museum }\end{array}$ & Sci. Lit. & Interest & Involvement \\
\hline SCI. LIT. & .195 & .335 & .163 & .000 & .000 & .000 \\
INTEREST & .597 & .055 & .131 & .165 & .000 & .000 \\
INVOLVEMENT & .420 & .203 & .211 & .167 & .306 & .000 \\
POLDEC & .186 & .075 & .072 & .153 & .215 & .160 \\
\hline
\end{tabular}

Education (0.395), reaching information about science (0.195), and visiting a science museum (.163) all have moderate positive direct effects on science literacy (cognition) (all, $\mathrm{p}<.001$ ). This provides evidence about our hypothesis that scientific literacy is determined by the level of cultural capital made of formal and informal educational activities. As for the affective element, reaching information about science $(0.565)$, visiting a science museum (.104) and scientific literacy (0.165) all have moderate positive direct effects on being interested in science news (affection) (all, $\mathrm{p}<.0001$ ). Information (0.032), visiting science museum(0.037) and education (.0.055) level have weak indirect effects (all, $\mathrm{p}<.001)$. Conative element, involvement through actively reading science articles and talking with friends about science, is affected by informedness (0.215), education (0.147), scientific literacy $(0.117)$ and interest $(0.306)$ and have moderate indirect effect for informedness (0.205) and weak for scientific literacy (0.051) and science museum (0.059). Finally, involvement (0.160), interest (0.166) and scientific literacy (0.099) have weakmoderate direct effects on participation to political decisions; whereas information $(0.186)$, education (0.075) science museum (0.072), scientific literacy (0.054) and interest (0.049) have weak indirect effects.

\section{Discussion}

These findings are interesting since all science related mental factors have higher effects than formal education level which is assumed to be a major determinant of informed political participation. This shows that being knowledgeable, interested and involved in science and technology related information is an important element of participation to political decisions. Hence, endowing citizens with S\&T related information is inevitable for a healthy functioning democracy.

Although scientific literacy plays a moderate role in political participation, it effects and is affected by different variables making the path to political participation. One third of its effect on participation is by indirect means, showing that its effects are mediated by other variables which make an important component of an informed society. 


\section{References}

1. Bourdieu, P., Practical reason: On the theory of action. Cambridge, UK: Polity Press., (1998).

2. Brossard, D. \& Shanahan, J., Do citizens want to have their say? Media, agricultural biotechnology, and authoritarian views of democratic processes in science. Mass Communication and Society, 6, 291-312, (2003).

3. George, R., \& Kaplan, D., A structural model of parent and teacher influences on science attitudes of eighth graders: Evidence from NELS. Science Education, 82, 93109, (1998).

4. Kasperson, R. E., Renn, O., Slovic, P., Brown, H. S. Emel, J., Goble, R., Kasperson, J. $\mathrm{X}$., \& Ratick, S., Social amplification of risk: a conceptual framework. Risk Analysis 8 (2), 177-188, (1988).

5. Miller, J., Civic Scientific Literacy in Europe and the United States. World Association for Public Opinion Research, Montreal, Canada National Science Education Standards . Washington, DC: The National Academies Press, 1996, (2006).

6. Rowe, G., \& Frewer, L. J. (2004). Evaluating public participation exercises: A research agenda. Science, Technology, and Human Values, 29(4): 512-556,

7. http://zacat.gesis.org 